\title{
Effects of Fillers of Animal Origin on the Physico-Mechanical Properties of Utility Polymer.
}

\author{
Ofora, Pauline U. ${ }^{1}$, Eboatu, Austine N. ${ }^{2}$, Arinze, Rosemary U. ${ }^{3}$ \\ And Nwokoye, Joy N. ${ }^{4}$ \\ (Deparment Of Pure \& Industrial Chemsitry, Nnamdi Azikiwe University, Awka, Nigeria.) $)^{1,23}$ \\ (Department Of Chemistry, Federal College Of Education, Umunze, Nigeria) ${ }^{4}$
}

\begin{abstract}
The effects of some animal materials, viz feather, hide and hoof, as fillers incorporated into propylene matrix were investigated. Composites of two varying weight percentages of fillers in fixed weight of the polymer resins were produced for each filler type by the injection moulding technique. The physicomechanical properties of the composites prepared showed positive effects in the properties such as, tensile strength, elongation at break, compressive strength, flexural strength and surface hardness. Polypropylene hide composite increased the tensile strength from $18 \mathrm{MPa}$ to $21 \mathrm{MPa}$ at $1 \%$ filler loading. The decrease in elongation at break was experienced for the three fillers incorporated into the propylene polymer matrix. The compressive and flexural strengths were seen to be enhanced by these fillers. These animal fillers gave polypropylene composites great strength by enhancing its mechanical properties with the hide filler showing the best reinforcing qualities. These materials of animal origin can be used as fillers and also as biodegradable fillers for polymer resins and mimic bio-plastics.
\end{abstract}

Keywords: Chicken feather, cow hide, hoof, mechanical properties and polypropylene matrix.

\section{Instroduction}

The wide variety of applications of polymers in almost all aspects of human activity shows the great importance of the plastic industry and growth in synthetic polymer technology [1]. New processing technologies lead to new applications of polymers (PIM, injection molding of organic sheets etc.) which put high demands on these materials. The basic endeavour of this research is to get a tough material that should be light, easy, processable and as "green" as possible.

It is known that plastics compete very favorably with wood and metals in the construction of buildings, under water constructions, automobile bodies and electronic gadgets [2]. This is because of their inherent properties which include corrosion resistance; resistance to water and chemicals, high dielectric constant, toughness, high strength, enhanced abrasion resistance, flex and moderate-to-high creep resistance and moderate temperature moulding characteristics. They can be made into many different colours and shapes. Today, these polymeric substances are truly indispensable to mankind, being essential and convenient for modern living [3]. Most materials of commerce though identified as single materials by their generic names are actually not monomaterials. Many additives are usually incorporated to impart desired physico-mechanical/chemical properties on the finished products. These additives (compounding agents) are carefully selected based on the desired performance target [4].

\section{a. Fillers shape and size impact}

\section{Materials and Methods}

Various components are added to the polymeric matrix to reach required properties of the material. In the literature, there are two main groups of fillers. The first group involves composites materials known as "filled materials". The volume fraction of the matrix is usually more than $50 \%$ and it is filled with some particles (talc, mica, clay etc.) [5], [6]. The shape and size of these particles affect all final composite properties (mechanical, rheological, physical etc.) [7].The second group of composite materials is called "reinforced materials". These composites are filled by short or long fibres (glass fibres, boron fibres, organic fibres, carbon fibres etc.) and volume of the matrix is usually less than 50\% [5], [6]. Each filler formation/ composition makes it possible to have polymer products of different mechanical properties [8]. Fillers used in this study are from natural animal origin namely; chicken feather, cow hide and hoof.

\section{b. Polymer Matrix}

Fillers (especially reinforced additives) should be combined with suitable matrix for taking several advantages. The most important functions of the matrix are to keep the fillers in the structure, to protect the fillers in the structure during fabrication and also to help to transfer the load. [9]. There are lots of different 
matrixes (metal, ceramic etc.) but we will deal with the thermoplastics matrix, (polypropylene). Semi crystalline thermoplastics are more efficiently reinforced than amorphous thermoplastics. In the plastic state the fillers act as nucleation sites for polymer crystallization (semi crystalline thermoplastics) and enhance the polymer crystallinity. Greater crystallinity is associated with a higher level of filler-matrix interaction [10], [11].

\section{c. Physico-Mechanical Properties Determination}

The mechanical properties of crystalline polypropylene, (PP), characterized in this work, from literature, are influenced by both degree of crystallinity and molecular weight [3]. A variety of methods are used to determine mechanical performance under a variety of loading conditions. These may be classified as static tests, transient tests, impact and cyclic tests. Static tests are used to measure the force response when a sample is strained, compressed, or sheared at a constant rate. These provide a means to characterize the mechanical properties of a polymer in terms of strength, modulus and elongation to failure [9]. It was based on this, that the mechanical properties of the polymer composites were characterized.

\section{a. Material Specification}

\section{Experimental Procedure}

Polypropylene is a semi crystalline thermoplastic with relatively low strength, toughness and high tenacity. It is flammable, with no moisture absorption and it is resistant to acids, alkalis and solvents. This material is very light and can reach high level of crystallinity. It is used in a wide variety of applications. Generally polypropylene with polyethylene (polyolefines) are the most world-wide used polymers [12].

The fillers of were adapted i.e.washed, cut into pieces and sun dried for two (2) weeks. These were ground to fine powder in the size of $200 \mu \mathrm{M}$.

\section{b. Polymer Composite Production}

The pelletized propylene resin was mixed with each of the fillers at $1 \%$ and $5 \%$ by weight. These were extruded as strands and made into small granules. This was done to ensure homogeneous mixing of the fillers and polymer resins. Later, each composition was fed into the hopper of an injection moulding machine (TL-1208.50 Model, Made in China), fixed with a rectangular shaped die of dimensions of $146 \mathrm{~mm}$ in length, $40 \mathrm{~mm}$ in width and $5 \mathrm{~mm}$ in thickness. After melting and compounding, the mixture was injected into the rectangular die and rectangular propylene composites test bars were produced.

\section{c. Mechananical Properties Measurement}

\section{i.) Determination of the tensile strength of the polymer composites}

The tensile properties of the filled polymer composites of Polypropylene, (PP), were measured using the Instron Universal Testing machine, ILAO TIEH Model 4501, Series IX (AMST I-20).A static load cell of $5 \mathrm{kN}$ was applied. The values of the tensile strength at break as well as the elongation at break and percentage elongation at break were recorded automatically. This was done on all the other composites separately. The results of the measurement are included in Table I.

\section{ii.) Determination of the compressive strength}

The compressive strength of the composites was measured using the Compressive Strength Testing machine of Model Cat G $43 / 2$, with a load capacity of $200 \mathrm{kN}$. The readings were automatically recorded and the values computed. The results of the measurement are included in Table 2.

\section{iii.) Determination of the flexural strength}

The flexural strength of the polymer composites was determined using a three-point bending jig clamped to the Flexural Strength testing machine of Model Cat L 18/D, with a load capacity of $250 \mathrm{kN}$. The stress developed at the surface of the test piece, supported near each end and loaded at the center, was measured automatically, for each specimen, and the values were computed. The results of the measurement are included in Table 3.

\section{iv.) Determination of the surface hardness}

The surface hardness of the polymer composites was measured by means of the Avery Hardness Testing machine, Type 6406, Number E65226. The corresponding value of the diameter of the indentation at that surface was recorded and the hardness was calculated with the formula as Birnell Hardness Number measured in $\mathrm{N} / \mathrm{mm}^{2}$;

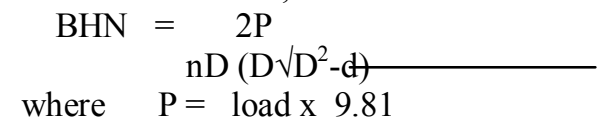


$\mathrm{D}=$ diameter of Indentor $(\mathrm{mm})$

$\mathrm{d}=$ diameter of impression $(\mathrm{mm})$ and

$\pi=3.142$

The results of the measurement are included in Table 4.

\section{Results and Discussion}

This is the stress at which the specimen breaks or ruptures, as measured in MPa. This stress at failure is called the 'ultimate stress'. It results from large and irreversible deformation, which is a sample rather than material property and is strongly influenced by sample defects and processing history. Tensile strength is the most common of the mechanical properties of polymers [13].

The polymer composites were characterized using $1 \%$ and $5 \%$ filler loading. This was based on the facts of some related preliminary studies carried out on the topic $[14,15]$.

Table 1 Values of tensile strength of PP composites

\begin{tabular}{|l|c|c|c|c|}
\hline $\begin{array}{l}\text { Polymer } \\
\text { Composites }\end{array}$ & $\begin{array}{l}\text { Tensile } \\
\text { S(Mpa) }\end{array}$ & $\begin{array}{l}\text { Elongation } \\
(\mathbf{m m})\end{array}$ & $\begin{array}{c}\text { Elongatio } \\
(\mathbf{\%})\end{array}$ & $\begin{array}{c}\text { Breakload } \\
(\mathbf{K N})\end{array}$ \\
\hline $\mathbf{0 \% P P}$ & 18 & 54.70 & 40.01 & 2.50 \\
\hline $\mathbf{1 \%} \%$ Feather & 19 & 44.92 & 30.56 & 0.72 \\
\hline $\mathbf{5 \%}$ Feather & 17 & 12.16 & 8.22 & 3.40 \\
\hline $\mathbf{1 \% H i d e}$ & 21 & 56.76 & 38.61 & 1.56 \\
\hline $\mathbf{5 \% H i d e}$ & 7 & 4.16 & 2.81 & 1.35 \\
\hline $\mathbf{1 \% H o o f}$ & 18 & 53.36 & 36.05 & 3.73 \\
\hline $\mathbf{5 \% H o o f ~}$ & 19 & 30.72 & 20.19 & 3.64 \\
\hline
\end{tabular}

Polypropylene composites showed higher tensile strength when compared with the unfilled polypropylene resin. This implies that, the incorporation of these fillers into polypropylene matrix improved the tensile strength, with the hide filler having the highest value at 1\% filler loading, and surprisingly lowest at 5\% filler loading. Feather filler on the other hand gave a high value at $1 \%$ filler loading, but on increasing the filler loading, the tensile strength was reduced slightly, while hoof filler gave increased strength as the filler loading increased as seen in Table1.

The decrease in the tensile strength of the polypropylene composites filled with hide may be explained thus, as the filler loading increases, the possibility of the formation of voids in the polymer layer next to filler surface also increases, causing tension concentration at the voids vicinity, generating the fractures, thus, a reduction in the tensile strength, resulting from an increase in filler loading. The same reason is also applicable to the feather filler which at $1 \%(19 \mathrm{MPa})$ and $5 \%(17 \mathrm{MPa})$ filler loadings respectively, a decrement was observed.

The hoof filler which slightly increased the tensile strength implied that the hoof filler enhanced the tensile strength of polypropylene resin. This is in agreement with some authors, who have already worked on related topic $[14,16,17,18]$.

Table 2: Values of compressive strength of PP composites

\begin{tabular}{|c|c|c|}
\hline $\begin{array}{c}\text { Polymer } \\
\text { Composites }\end{array}$ & $\begin{array}{c}\text { Test force } \\
(\mathbf{K N})\end{array}$ & $\begin{array}{c}\text { Compressive Strength } \\
\left(\mathbf{N} / \mathbf{m m}^{2}\right)\end{array}$ \\
\hline $0 \%$ PP & 269.80 & 84.30 \\
\hline $1 \%$ Feather & 218.80 & 68.40 \\
\hline $5 \%$ Feather & 146.50 & 45.80 \\
\hline $1 \%$ hide & 201.40 & 62.90 \\
\hline $5 \%$ Hide & 274.20 & 85.70 \\
\hline $1 \%$ Hoof & 179.50 & 56.10 \\
\hline $5 \%$ Hoof & 216.20 & 67.60 \\
\hline
\end{tabular}

The result of the compressive strength of the unfilled polypropylene as shown in Table 2 gave a higher value than the filled ones, except with $5 \%$ hide filler load. Hence, a decrease in the effect of the fillers on the compressive strength of the polypropylene was observed in all the cases. Among, the filled composites, the fillers (hide and hoof), increased the compressive strength, but feather, showed a decrease in the compressive strength. This decrease in the compressive strength of the polypropylene composites among the three fillers could be due to the filler particles that tied the bond chains and filled the interstitial voids thereby creating no space for the external force applied in the form of test force, thus reducing the compressive strength. This reduction could be as a result of weak adhesion between the polymer and filler, lack of coupling agent and particle size, since the incorporation of these fillers decreased the compressive strength. 
Table 3: Values of flexural strength of PP composites

\begin{tabular}{|l|c|c|}
\hline Polymer Composites & $\begin{array}{c}\text { Test force } \\
\text { (KN) }\end{array}$ & $\begin{array}{c}\text { Flexural strength } \\
\left(\mathbf{N} / \mathbf{m m}^{\mathbf{2}}\right)\end{array}$ \\
\hline 0\% PP & 0.38 & 1.34 \\
\hline 1\% Feather & 0.68 & 2.39 \\
\hline 5\% Feather & 0.36 & 1.27 \\
\hline 1\% hide & 0.24 & 0.84 \\
\hline 5\% Hide & 0.37 & 1.30 \\
\hline 1\% Hoof & 0.47 & 1.65 \\
\hline 5\% Hoof & 0.26 & 0.92 \\
\hline
\end{tabular}

Polypropylene composites filled with feather and hoof at $1 \%$ filler loading increased the flexural strength when compared with the unfilled polypropylene specimen, but decreased as the filler loading increased, while hide filler decreased the strength below the value of the unfilled specimen, as shown in Table 3. The specificity of the actions of these three fillers on the polypropylene polymer resins cannot be overlooked or ignored.

The decrease in the flexural strength as the filler loading increased could still be explained once again with the fact that as filler loading is increased, rigidity and hardness are increased, thereby bringing down the resin chain flexibility. This is in accordance with the observations previously made by some other researchers $[15,20]$.

Table 4: Readings of surface hardness of PP composites

\begin{tabular}{|c|c|c|c|c|}
\hline $\begin{array}{c}\text { Polymer } \\
\text { Composites }\end{array}$ & $\begin{array}{c}\text { Diameter of } \\
\text { indentor } D \text {, } \\
(2 \mathrm{~mm})\end{array}$ & $\begin{array}{l}\text { Load } \\
(5 \mathrm{Kg})\end{array}$ & $\begin{array}{l}\text { Diameter of } \\
\text { indentation } d \text {, } \\
(\mathrm{mm})\end{array}$ & $\begin{array}{l}\text { BHN } \\
\left(\mathrm{N} / \mathrm{mm}^{2}\right)\end{array}$ \\
\hline PP $0 \%$ Filler & $2 \mathrm{~mm}$ & $5 \mathrm{~kg}$ & 0.5 & 4.1722 \\
\hline PP1\%Feather & $2 \mathrm{~mm}$ & $5 \mathrm{~kg}$ & 0.5 & 4.1722 \\
\hline PP5\%Feather & $2 \mathrm{~mm}$ & $5 \mathrm{~kg}$ & 0.5 & 4.1722 \\
\hline PP $1 \%$ Hide & $2 \mathrm{~mm}$ & $5 \mathrm{~kg}$ & 0.5 & 4.1722 \\
\hline PP $5 \%$ Hide & $2 \mathrm{~mm}$ & $5 \mathrm{~kg}$ & 0.4 & 4.1139 \\
\hline PP $1 \%$ Hoof & $2 \mathrm{~mm}$ & $5 \mathrm{~kg}$ & 0.4 & 4.1139 \\
\hline PP $5 \%$ Hoof & $2 \mathrm{~mm}$ & $5 \mathrm{~kg}$ & 0.3 & 4.0579 \\
\hline
\end{tabular}

Polypropylene composites showed an irregular trend, Table 4. This could be attributed to the fact that the addition of these fillers to the polymer matrices affected the adhesion strength between the polymers and fillers. This can be explained by means of an analysis of polymer-filler interactions. The presence of electrons in the fillers and polymers may have caused repulsion that affected the surface hardness, since there was no donor or acceptor of electrons, thereby reducing crosslinking density and consequently, there was no additional physical crosslinks within the polymer network, Thus, the surface hardness was meaningless [21] or it could mean that the fillers were evenly distributed on the polymer matrix, thereby showing slight surface resistance.

\section{Conclusion}

These fillers namely, feather, hide and hoof have shown their effects on the polypropylene composites at different filler loadings. Thus, the mechanical properties of the composites produced were found to depend on polymer matrix-filler interaction, particle size and distribution of the fillers particles within the matrix. It could be deduced that these properties could make these composites to be desirable for some applications where less strength and high stiffness is required. However, the extent of reinforcement was perhaps due to the interaction between the organic phase of the filler and organic polymer.

Hide filler exhibited better reinforcing performance on the polymer resins, followed by feather and lastly hoof. This could be attributed to the nature of hide and also confirms the good and durable leather products made from hide. The qualities also revealed by feathers showed an interesting value for feathers. This may be due to its high keratin content and other desirable qualities, leading to its increasing demand by researchers to convert feathers into bio-plastics resins and carbon fibers.

Generally, the use of feather, hide and hoof as fillers have embedded some significant properties that are advantageous to polypropylene. Therefore, it is pertinent to channel these fillers into use as fillers for thermoplastic resins and more especially the feathers which are not being used but mainly seen and disposed as wastes. The recent interest in feathers by world researchers should also be supported.

These fillers are proteinous materials that can decompose and degrade. So the need to use them as biodegradable fillers incorporated into polymers (plastics which litter the environment and seen at landfills) is strong, to help in keeping the environment clean. Also, they can be used to form bio-plastics due to the mechanical strength property, they displayed; thereby reducing dependence on the polymer resins produced from petrol. 


\section{References}

[1]. H. Morawetz, Polymers: The Origins and Growth of a Science (New York: John Wiley and Sons, 1985).

[2]. G.A. Cook,Survey of Modern Industrial Chemicals (Michigan: Ann Arbor Publishing Co., 1975) $248-257$.

[3]. F.W. Billmeyer, Jnr, Textbook of Polymer Science ( $3^{\text {rd }}$ Ed.) (Toronto: John Wiley and Sons, 2005) 3, 344-345, 368

[4]. M.S. Bhatnagar, A Textbook of Polymers: Chemistry and Technology of Polymer; Processing and Applications (New Delhi: Chand, 2004).

[5]. V. VASILIEV, V. MOROZOV and V. Evgeny, Mechanics and analysis of composite materials (Amsterdam : Elsevier, 2001). Time and time dependent loading effects, pp. 1,319-332,365. ISBN 0-08-042702-2.

[6]. A. Kumar, R. Gupta, and K. Rakesh Fundamentals of polymer engineering. (2 ${ }^{\text {nd }}$ Ed.), ( New York : Marcel Dekker, 2003), 103107.

[7]. R.Rothon, and M. Hancock, General principles guiding selection and use of particulate materials, in R.N. Rothon, Particulate-filled polymer composites, ( $2^{\text {nd }}$ Ed.) (UK : Rapra technology limited, 2003) 17-19.

[8]. R. Cain, M. Pinfold and K.A. Lindsey, General Properties of Composites : Stiffness, Strength and Toughness in N. Tucker, K. Lindsey, An introduction to automotive composites, (Ist Ed.) (UK : Rapra technology limited, 2002.) 59-61.

[9]. L.A. Berglund, Polymeric matrix system : Thermoplastics resins, in S.T. Peters, Handbook of composites, (2 $2^{\text {nd }}$ Ed.) ( London : Chapman \& Hall, 1998) 115-131.

[10]. D.D.L. Chung, Carbon fiber composites. 2nd edition.( Massachusetts : Butterworth Heinemann, 1994) 85-102.

[11]. S. Saiello, J. Kenny and L. Nicolais, Interface morphology of carbon fibre/PEEK composites. Journal of materials science 25, 1990, 3496-3496.

[12]. J.A, Brydson, Plastics materials. (7 ${ }^{\text {th }}$ edition) (Oxford : Butterworth Heinemann, 1999), Aliphatic polyolefins other than polyethylene and diene rubbers, 247-268.

[13]. J.R. Fried, Polymer Science and Technology 2nd edn., (New Delhi: PHI Learning Private Ltd., 2009).

[14]. J.N. Afiaukwa, A.N. Eboatu and M.U. Akpuaka, The Effects of Some Plant Materials on the Mechanical Properties of Polypropylene.Journal of Applied Polymer Science, 90 (6), 2003, 1447-1452.

[15]. I.O. Eze, The Mechanical Properties of Bamboo powder Filled Virgin and Recycled Low Density Polyethylene Composites, M.Sc Thesis, Federal University of Technology Owerri, Nigeria, 2010.

[16]. D. He and B. Jiang, Effect of Filler Addition on Mechanical, Thermal and Electrical Properties of Mica/Nylon-6 Composites, Journal of Applied Polymer Science, Vol.49, 1993, 617.

[17]. I.C. Maduafor, Mechanical Properties of Cassava-Filled Linear Low Density Polyethylene Composites International Research in Engineering, Science and Technology, 4 (2), 2007, 143-151.

[18]. F. Bueche, Physical Properties of Polymers (New York: Robert E. Krieger Publishing Company, Hunting-ton, 1979) 52-60.

[19]. F. Aguele, Comparative Analysis of the Effects of Selected Fillers from Renewable Sources on Reinforcing Properties of Natural Rubber Composites, M.Sc Thesis, Federal University of Technology, Owerri, Nigeria, 2010.

[20]. R.C.R. Nunes, J.L.C. Fonseca and M.R. Pereira, Polymer-Filler Interactions and Mechanical Properties of a Polyurethane Elastomer, Polymer Testing, 19 (1), 2000, 93-103.

[21]. I.O. Eze, The Mechanical Properties of Bamboo powder Filled Virgin and Recycled Low Density Polyethylene Composites, M.Sc Thesis, Federal University of Technology Owerri, Nigeria, 2010. 